\title{
Two Perceived Dimensions of Technology Acceptance Model in Mobile Tourist Guide Context
}

\author{
Numtip Trakulmaykee, Yaowalak Trakulmaykee, and Khanungnit Hnuchek
}

\begin{abstract}
The purpose of this study is to examine the new technology acceptance model that is appropriate to predict users' intention to use mobile tourist guide. In this study, we propose the new model which is developed based on the original technology acceptance model. Statistical analysis is employed to evidence the advantage of new proposed model. In order to investigate efficiently, this study uses SmartPLS using PLS Algorithm to analyse dataset which collects data from tourists via survey questionnaire. The findings in this study reveal that the proposed model is more appropriate than original technology acceptance model to predict and explain users' acceptance technology in the context of mobile tourist guide. All proposed factors in the first dimension (perceived usefulness, perceived ease-of-use and perceived compatibility) and second dimension (perceived content quality, perceived interaction quality and perceived appearance quality) are the factors of users' intention to use mobile tourist guide.
\end{abstract}

Index Terms-Intention, mobile, technology acceptance model, tourist guide.

\section{INTRODUCTION}

Users' acceptance of information technology has been considered as successful measure of technology adoption in variety of contexts. Without users' acceptance, the new technology will be waste and useless. Therefore, the Technology Acceptance Model (TAM) has been continuously employed to study the users' acceptance. The TAM was proposed by [1] in 1989, it explains how and when users will use technology. Nowadays, the users' acceptance technology still is studied in the new technologies in particular of mobile application in several contexts. As a result of difference in technological features, the users' acceptance and users' perception still need to study in each technology and user group [2], [3].

Mobile tourist guide (MTG) is application on mobile devices for tourists to get tour information such as maps, attractive places, accommodations, transportations, and local food. As a result of mobile limitations, the design and development of mobile applications are different from information systems on computer. Therefore, mobile developers need to focus on design qualities (e.g., content quality, interaction quality, appearance quality) in order to fix the mobile limitations such as small screen, limited

Manuscript received September 20, 2014; revised October 15, 2015.

Numtip Trakulmaykee is with the Prince of Songkla University, Songkhla, Thailand (e-mail: t.maykee@gmail.com).

Yaowalak Trakulmaykee and Khanungnit Hnuchek are with Hadyai University, Songkhla, Thailand (e-mail: yoawalak@hotmail.com, khanit_k@hotmail.com). storage and computed speed. Furthermore, most tourists always use tour information on their move, and then their perception in compatibility possibly influences their intention to use MTG.

In this paper, we propose the new technology acceptance model to explain the factors of tourists' intention to use MTG. The proposed model is developed based on TAM [1] and examined by statistical analysis. The findings of this study will be the evidence to reveal appropriate technology acceptance model in the context of MTG.

\section{RELATED WORKS}

\section{A. Technology Acceptance Model}

The TAM has received considerable attention of researchers in the information technology (IT) field over the past decade. Previous researches have demonstrated the validity of TAM across a wide range of IT [4-6]. TAM is used to predict and explain technological usage, it posit two primary determinants of IT acceptance. The first determinant is perceived usefulness (PU) which is defined as as the degree to which person believes that using a particular system would enhance his or her performance. The second determinant is perceived ease-of-use (PEU) which is defined as the degree to which person believes that using a particular system would be free of effort. Both PU and PEU influence user's behavioural intention to use technology. Additionally, PEU also influence PU in TAM [1].

Although TAM is widely used to study technology in variety of contexts, TAM does not concern on quality factors and other important factors related to users' intention to use technology. Consequently, TAM has been adapted by IT researchers or integrated with other theories in order to provide a more comprehensive model structure for predicting users' intention to use technology. In this paper, we propose four determinants which possibly influence on tourists' intention to use MTG: perceived compatibility (PCP), perceived content quality (PCQ), perceived interaction quality (PIQ), and perceived appearance quality (PAQ).

\section{B. Perceived Compatibility $(P C P)$}

Nowadays the technology devices are developed based on the supporting task and lifestyle of users. The compatibility has been one of the most important factors of users' intention to use technologies [2]. In general, high incompatibility will decreases the likelihood of adoption [7]. Users will be unwilling to accept a new technology if that technology is not compatible with their works [8]. Likewise, 
Ref. [9]-[11] highlighted the role of lifestyle that it is a key factor in determining the adoption rate. Therefore, tourists' perception in compatibility possibly influence on tourists' intention to use MTG. In this study, PCP focuses on users' lifestyle and travel style. PCP is defined as the degree to which an innovation is perceived as being consistent with the existing values, needs and past experiences.

\section{Perceived Content Quality (PCQ)}

The content quality is important to success the IT adoption [12]-[17], it has been highlighted when firms want to design and develop mobile information services for their customers. Ref. [18] identified the role of information quality in the success of information system. In the context of digital tourist guides on mobile phones, Ref. [19] also highlight the importance of content quality. They suggested that the providing contents should be valuable, updated and high quality. Similarity, Ref. [20] reported the importance of sufficient information in mobile information service for tourist. Tourists need the tour information about accommodation, food and transportation. Therefore, this study considers PCQ to be a factor of users' intention to use MTG. In this study, PCQ focuses on content quality in terms of sufficient content, up-to-date, completeness and accuracy. PCQ is defined as the degree of perception in quality of the content that is provided by the MTG to satisfy tourists' needs.

\section{Perceived Interaction Quality (PIQ)}

Interaction quality has been considered in IT studies since a last decade. Ref. [21] highlighted that most users will consider interaction as one of their expected qualities. He noted that users' dissatisfaction will relate to interaction that is not intuitive, easy, understandable, responsive, and pleasant. In mobile applications, the interaction quality is considered as an important usability issue because the input device on the small screen needs a high level of efforts while interacting with mobile devices $[22,23]$. Therefore, in the context of MTG, users' perception in interaction quality is considered to be a factor of users' intention to use MTG. In this study, PIQ focuses on usability in terms of structure, navigation, and consistency on mobile information application. A consistent design of menus guarantees easy access to the desired information [24]. PIQ is defined as the degree of perception in the level of achievement which the MTG provide easy and efficient methods of interaction.

\section{E. Perceived Appearance Quality (PAQ)}

The appearance quality is critical helping to meet users' expectation on mobile application because of the small screen and inconvenient input [16]. Mobile application must include short and concise textual descriptions accompanied by pictures and multimedia content used to provide user information [24]. Moreover, mobile application should follow a hierarchical multi-level structure that helps users to easily search their interesting information. Ref. [25] demonstrated in their study that appearance design and interface style should be considered for group of target users. Likewise, Ref. [26] highlighted the expectant quality and perception quality as appearance quality associated with users' satisfaction to use technology. Therefore, users' perception in appearance quality may be a factor of users' intention to use MTG. In this study, PAQ focuses on the perception in quality of display screen in terms of attractiveness, proper organized design, layout, and proper multimedia. PAQ is defined as the degree of perceived display screen in terms of clear and understandable presentation on mobile screen.

\section{MEthodology}

In statistical analysis, we use the data set which is collected from tourists using survey questionnaire. All measures in questionnaire are adapted from good reliable items which Cronbach's alpha values exceed 0.70 as presented in Appendix. To ensure the effectiveness of questionnaire, the pilot test is used before data collection stage. In pilot test, the questionnaires are distributed to 30 convenient tourists at Suvarnabhumi Airport in Thailand. Finally, the completed questionnaires are distributed to tourists using convenience sampling technique. Before filling out the questionnaire, the MTG usage and MTG features are demonstrated to users and then users have the chance to try out the MTG. The number of total cases is 684 that is sufficient to analyse with confirmatory factor analysis [27].

To evaluate the proposed model, we analyse data set with a confirmatory factor analysis using SmartPLS. The SmartPLS is powerful Structural Equation Modelling (SEM) software to analysis data. In the first step, the measurement analysis is used to examine in terms of validity and reliability of measures. Next, the model analysis is used to evaluate three models and compare results.

Model 1 is original TAM which has two factors (PU and PEU) to influence users' intention to use MTG.

Model 2 has three factors (PU, PEU and PCP). This model has three generic perceptions which are two original perceptions from TAM and PCP.

Model 3 has five factors (PU, PEU, PCP, PCQ, PIQ and PAQ), two factors are original factors in TAM and the other three factors are extended factors. Thus, the perceptions in this model consist of three generic perceptions and three quality perceptions. The Model 3 is the proposed model of this study.

\section{StATISTICAL ANALYSIS AND RESULtS}

In this section, we analyse the measurement in terms of reliability and validity. Then the comparison results of three models are demonstrated in model analysis subsection.

\section{A. Measurement Analysis}

The reliability and validity are established by factor loading, composite reliability (CR), average variance extracted (AVE), and variance inflation factors (VIF) as presented in Table I. The factor loadings of all items also are higher than 0.60, which consider to be acceptable measurement [27]. The AVE of each variable is above 0.50, thus the convergent validity of this study is adequate. The $\mathrm{CR}$ values in this study range from 0.93 to 0.97 , which indicate the reasonable reliability level $(\mathrm{CR}>0.70)$ for the measured items.

Discriminant validity is tests correlations between 
variables. To test the discriminant validity, the values of square root of AVE are computed as diagonal elements. These values should exceed the inter-construct correlations for adequate discriminant validity. As shown in Table II, all diagonal elements in this study are larger than their corresponding correlation coefficients, and all correlation of constructs are significant $(p<0.01)$. Thus, the discriminant validity of study is acceptable. The VIF of each variable also is less than the acceptable cut-off points of value 5 [27]. It indicates this study does not have any multicollinearity problem, and then this study can continue to analyse model using confirmatory factors analysis.

\begin{tabular}{|c|c|c|c|c|}
\hline Variable & Item & Loading & $\mathrm{CR}$ & AVE \\
\hline $\begin{array}{l}\text { Perceived } \\
\text { usefulness } \\
\text { (PU) }\end{array}$ & $\begin{array}{l}\text { PU1 } \\
\text { PU2 } \\
\text { PU3 } \\
\text { PU4 }\end{array}$ & $\begin{array}{l}0.82 \\
0.92 \\
0.87 \\
0.89\end{array}$ & 0.93 & 0.77 \\
\hline $\begin{array}{l}\text { Perceived } \\
\text { ease-of-use (PEU) }\end{array}$ & $\begin{array}{l}\text { PEU1 } \\
\text { PEU2 } \\
\text { PEU3 } \\
\text { PEU4 }\end{array}$ & $\begin{array}{l}0.92 \\
0.95 \\
0.94 \\
0.93\end{array}$ & 0.97 & 0.87 \\
\hline $\begin{array}{l}\text { Perceived } \\
\text { compatibility } \\
(\mathrm{PCP})\end{array}$ & $\begin{array}{l}\text { PCP1 } \\
\text { PCP2 } \\
\text { PCP3 } \\
\text { PCP4 }\end{array}$ & $\begin{array}{l}0.92 \\
0.95 \\
0.94 \\
0.93\end{array}$ & 0.96 & 0.89 \\
\hline $\begin{array}{l}\text { Perceived } \\
\text { content quality } \\
\text { (PCQ) }\end{array}$ & $\begin{array}{l}\text { PCQ1 } \\
\text { PCQ2 } \\
\text { PCQ3 } \\
\text { PCQ4 }\end{array}$ & $\begin{array}{l}0.86 \\
0.89 \\
0.90 \\
0.88\end{array}$ & 0.93 & 0.78 \\
\hline $\begin{array}{l}\text { Perceived } \\
\text { appearance quality } \\
\text { (PAQ) }\end{array}$ & $\begin{array}{l}\text { PAQ1 } \\
\text { PAQ2 } \\
\text { PAQ3 } \\
\text { PAQ4 }\end{array}$ & $\begin{array}{l}0.89 \\
0.89 \\
0.91 \\
0.92\end{array}$ & 0.94 & 0.80 \\
\hline $\begin{array}{l}\text { Perceived } \\
\text { interaction quality } \\
\text { (PIQ) }\end{array}$ & $\begin{array}{l}\text { PIQ1 } \\
\text { PIQ2 } \\
\text { PIQ3 } \\
\text { PIQ4 }\end{array}$ & $\begin{array}{l}0.91 \\
0.94 \\
0.91 \\
0.87\end{array}$ & 0.95 & 0.82 \\
\hline $\begin{array}{l}\text { Intention to use } \\
\text { MTG (INU) }\end{array}$ & $\begin{array}{l}\text { INU1 } \\
\text { INU2 } \\
\text { INU3 } \\
\text { INU4 }\end{array}$ & $\begin{array}{l}0.89 \\
0.90 \\
0.79 \\
0.92\end{array}$ & 0.93 & 0.77 \\
\hline
\end{tabular}

\begin{tabular}{lccccccc}
\multicolumn{7}{c}{ Table II: CoRrelation ANALysis } \\
\hline \multicolumn{1}{c}{ PU } & PEU & PCP & PCQ & PAQ & PIQ & INU \\
\hline PU & $\mathbf{0 . 8 8}$ & & & & & & \\
PEU & 0.65 & $\mathbf{0 . 9 3}$ & & & & & \\
PCP & 0.60 & 0.52 & $\mathbf{0 . 9 4}$ & & & & \\
PCQ & 0.68 & 0.51 & 0.69 & $\mathbf{0 . 8 8}$ & & & \\
PAQ & 0.60 & 0.56 & 0.63 & 0.64 & $\mathbf{0 . 9 0}$ & & \\
PIQ & 0.65 & 0.62 & 0.51 & 0.69 & 0.75 & $\mathbf{0 . 9 1}$ & \\
INU & 0.64 & 0.70 & 0.72 & 0.68 & 0.64 & 0.61 & $\mathbf{0 . 8 8}$ \\
\hline \multicolumn{1}{c}{}
\end{tabular}

\section{B. Model Analysis}

Fig. 1 presents the analysed results of Model 1 which has two factors (PU and PEU) of intention to use MTG. The effects of PU $(\beta=0.52, p<0.001)$ and $\operatorname{PEU}(\beta=0.52, p<$ 0.001 ) on intention to use MTG is quite strong. Furthermore, PEU has direct effect on PU $(\beta=0.65, p<$ $0.001)$. These results are similar to the results in TAM. However, PU and PEU can explain only $42.1 \%\left(R^{2}\right)$ of observation variance in intention to use MTG.

To increase the $R^{2}$ value, the appropriate variables should be included in model. Therefore, the PCP is included in Model 2 and examined in order to ensure the appropriation of additional factor. The $R^{2}$ value of Model 2 is 0.519 and $\Delta R^{2}$ is 0.098 as presented in Fig. 2, thus Model 2 is more appropriate to explain tourists' intention to use MTG than Model 1. The effects of PU $(\beta=0.23, p<0.001)$ and PEU $(\beta=0.26, p<0.01)$ on intention to use MTG is significant. The PEU has direct effect on PU $(\beta=0.65, p<0.001)$. In addition, the result shows that PCP has the largest direct effect on tourists' intention to use MTG $(\beta=0.45, p<$ 0.001). Therefore, PCP should be included into TAM to efficiently predict and explain international tourists' intention to use MTG.

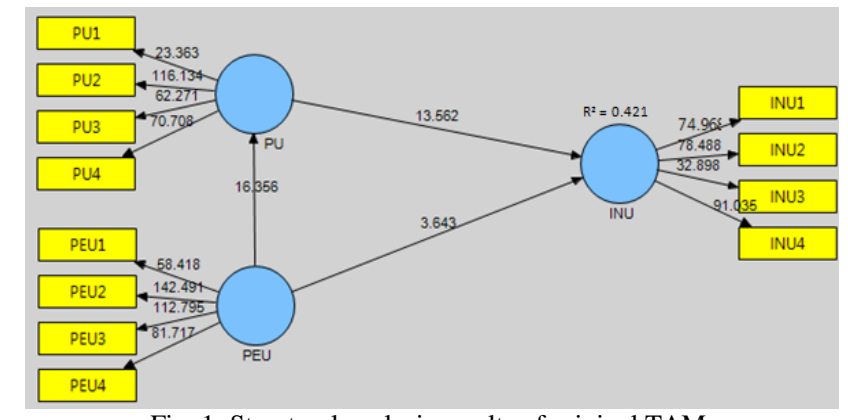

Fig. 1. Structural analysis results of original TAM.

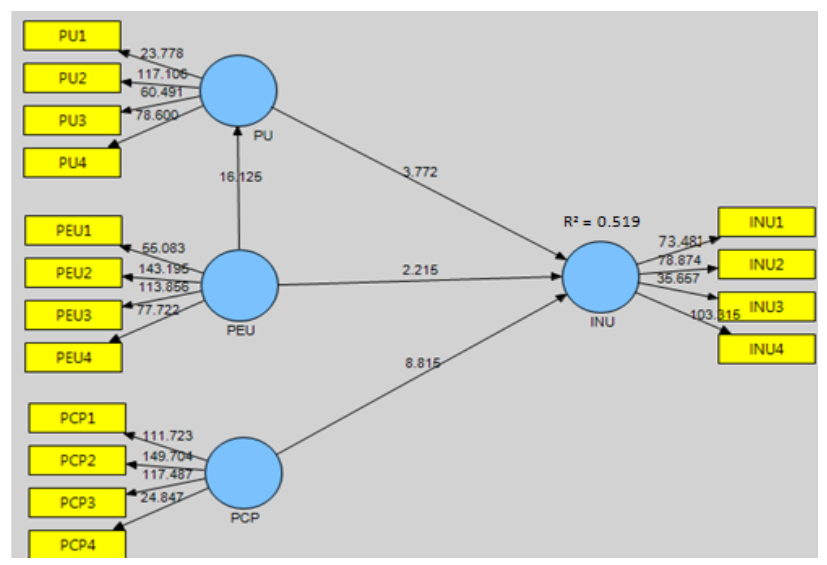

Fig. 2. Structural analysis results of Model 2.

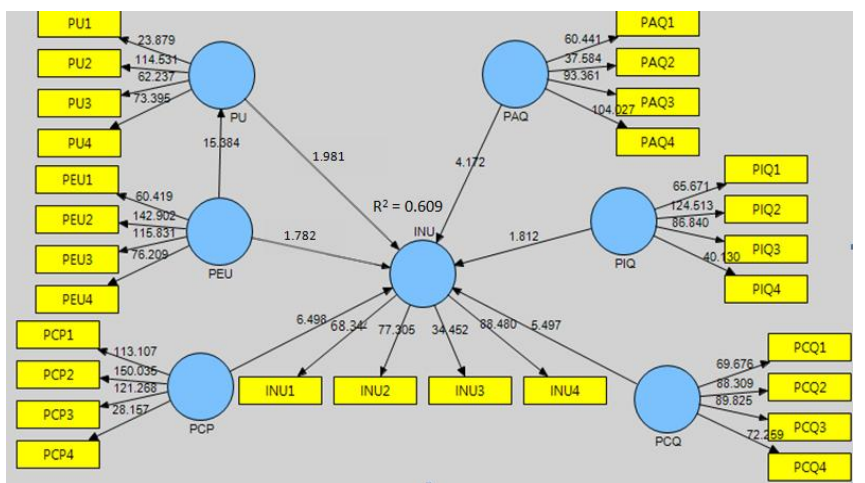

Fig. 3. Structural analysis results of Model 3.

As can be seen in Fig. 3, the proposed model or Model 3 can explain and predict users' intention to use MTG more than the original TAM or Model $1\left(R^{2}=0.609, \Delta R^{2}=0.188\right)$. From structural analysis, all t-values (1-tailed) exceed 1.65 then every relationship in proposed model is significant. It indicates that the direct factors of tourists' intention to use MTG are PU $(\beta=0.08, p<0.05)$, PEU $(\beta=0.01, p<0.05)$, PCP $(\beta=0.33, p<0.001)$, PCQ $(\beta=0.25, p<0.001)$, PIQ $(\beta=0.09, p<0.05)$, and PAQ $(\beta=0.22, p<0.001)$. In the context of MTG, the direct effect PCP on tourists' intention is the largest effect. It indicates that international tourists 
concern about the compatibility more than the other factors, especially the two factors (PU and PEU) of original TAM. Furthermore, PEU also has the positive roles on PU $(\beta=$ $0.65, p<0.001)$.

\section{DISCUSSION}

Based on the existing theory of TAM, this study presents and validates the proposed model that explains international tourists' intention to use MTG. The results report the same results in TAM and previous studies [4]-[6] that PU and PEU have positive impacts on intention to use MTG and PEU has a positive impact on PU. However, this study demonstrate that only two factors in TAM (PU and PEU) are not enough to explain and predict international tourists' intention to use mobile technology in the context of MTG. PCP, PCQ, PIQ and PAQ should be included in MTG acceptance model. Therefore, the theoretical contribution of this study is our proposed model that can explain and predict international tourists' intention to use MTG more than the original TAM in particular of users' perception.

For practical contribution, our empirical study provides the guidance for MTG providers and MTG developers. The findings indicate that the significant perceptions of international tourists' intention to use MTG are both generic perceptions (PU, PEU and PCP) and quality perceptions (PCQ, PIQ and PAQ). Especially, PCP, PCQ and PAQ strongly impact international tourists' intention to use MTG.

Among the five user's perception, PCP has the strongest effect on intention to use MTG. This is consistent with earlier studies [10], [11] that users' lifestyle will strongly affect their decision to use the mobile technology. Thus, MTG providers should carefully consider the issues of compatibility to ensure that their offering meets their users' travel style and lifestyle. The example is that most international tourists want to taste the local food and need the recommended restaurants nearby their location, thus the map and guide detail (location-based information) are very important for them. However, the providers and developers should consider the internet connection, free WIFI and internet fee in their countries. If they provide only online contents in their MTG and their international tourists cannot connect internet, then the MTG is not compatible in international tourists' travel.

In terms of quality perception, the results of this study suggest that providers and developers need to recognise the limitations of mobile devices (e.g., screen size, memory, processing power, storage and user interface). The results indicate that all quality perceptions are stronger impacts on international tourists' intention to use MTG than PU and PEU. International tourists understand the limitations of mobile devices, thus they do not expect a lot of contents in MTG. They need only sufficient tour contents that can support their travel. However, the tour contents should be up-to-date, accurate and reliable. Furthermore, the providers and developers should consider the appearance quality. The display screen should design and develop based on attractive presentation, appropriate layout, proper multimedia, and proper font and colour [24]-[26]. Consistent with the existing studies [22], [23], interaction quality is a factor on users' intention to use mobile application. However, in context of MTG, international tourists less concern about it because users have the experiences in mobile applications today and they know how to interact with mobile applications. Therefore, providers and developers can provide and design MTG without a lot of thoughtfulness in terms of interaction design.

As a main limitation of the study, this paper focuses on users' perceptions as factors of intention to use MTG. Future research should also broaden the model including possible factors which may influence on international tourists' intention such as technology experience and travel experience.

\section{CONCLUSION}

This study reveals the factors of international tourists' intention to use mobile application in the context of MTG. The results from analysis in this study have several contributions in terms of theoretical and practical aspects. For the theoretical contribution, this paper proposes the framework of users' intention to use MTG in terms of users' perceptions. Our empirical study reveals that five user' perceptions will influence on their intention to use MTG. It can be the evidence to confirm that original TAM cannot be the appropriate model to predict and explain tourists' intention to use technology in the context of MTG. For the practical contribution, the results of study provide the understandings of international tourists' MTG perceptions. In order to achieve any mobile adoption projects, tourism providers and tourism departments should focus on these factors in terms of MTG development and MTG providing for international tourists.

\section{APPENDIX: A MEASUREMENT IN THIS STUDY}

\begin{tabular}{|c|l|c|}
\hline Item & \multicolumn{1}{|c|}{ Measure } & $\begin{array}{c}\text { Adapted } \\
\text { Source }\end{array}$ \\
\hline PU1 & Ease of access tour information & {$[28],[29]$} \\
PU2 & Speed of access tour information & \\
PU3 & Time saving for trip planning & \\
PU4 & Effectiveness & {$[29],[30]$} \\
\hline PEU1 & Ease of learning & \\
PEU2 & Ease of use & \\
PEU3 & Level of effort & {$[11],[29]$} \\
PEU4 & Level of understanding & \\
\hline PCP1 & Compatibility in travel & \\
PCP2 & Compatibility in travel style & {$[16]$} \\
PCP3 & Compatibility in life style Compatible & \\
PCP4 & usage via mobile devices & \\
\hline PCQ1 & Need sufficiency & {$[12],[16]$} \\
PCQ2 & Up-to-date & \\
PCQ3 & Accuracy & \\
PCQ4 & Reliability & {$[23]$} \\
\hline PAQ1 & Attractive presentation & \\
PAQ2 & Appropriate layout & \\
PAQ3 & Proper font and color & \\
PAQ4 & Proper multimedia & \\
\hline PIQ1 & Ease of moving back & \\
PIQ2 & Design consistency & \\
PIQ3 & Navigation & \\
PIQ4 & Menu awareness & \\
\hline INU1 & Usage for planning trip & \\
INU2 & Usage in during trip & \\
INU3 & Usage for sharing trip experiences & \\
INU4 & Usage in the next trip & \\
\hline & & \\
\hline
\end{tabular}




\section{ACKNOWLEDGMENT}

This work was supported in part by a grant from Faculty of Science and Prince of Songkla University.

\section{REFERENCES}

[1] F. Davis, "Perceived usefulness, perceived ease of use, and user acceptance of information technology," MIS Quarterly, vol. 13, no. 3 pp. 319-340, 1989.

[2] E. M. Rogers, Diffusion of Innovations, 5th ed, New York: Free Press, 2003.

[3] C. L. Hsu, H. Lu, and H. H. Hsu, "Adoption of the mobile internet: An empirical study of multimedia message service (MMS)," Omega, vol. 35, no. 6, pp. 715-726, 2007.

[4] I. L. Wu, J. Y. Li, and C. Y. Fu, "The adoption of mobile healthcare by hospital's professionals: An integrative perspective," Decision Support Systems, pp. 587-596, 2011.

[5] M. Featherman and J. Wells, "The intangibility of e-services: effects on perceived risk and acceptance," ACM SIGMIS Database, vol. 41, no. 2, pp. 110-131, 2010.

[6] A. N. Giovanis, S. Binioris, and G. Polychronopoulos, "An extension of TAM model with IDT and security/privacy risk in the adoption of internet banking services in Greece," EuroMed Journal of Business, vol. 7 , no. 1 , pp. $24-53,2012$

[7] R. Hill and I. Troshani, "A conceptual framework and propositions for the acceptance of mobile services," Journal of Theoretical and Applied Electronic Commerce Research, vol. 2, no. 2, pp. 61-73, 2007.

[8] R. Z. Kuo and G.-G. Lee, "Knowledge management system adoption: exploring the effects of empowering leadership, task-technology fit and compatibility," Behaviour \& Information Technology, vol. 30, no. 1, pp. 113-129, 2011.

[9] C. C. Tao, "An integrated approach to segment mobile commerce market on the train," in Proceedings of International Joint Conference on Neural Networks, Hong Kong, pp. 1145-1150, 2008.

[10] G. Putzer and Y. Park, "The effects of innovation factors on smartphone adoption among nurses in community hospitals," American Health Information Management Association, vol.7, pp. 1$20,2010$.

[11] Y. Lu, et al., "Dynamics between the trust transfer process and intention to use mobile payment services: A cross-environment perspective," Information and Management, vol. 48, pp. 393-403, 2011.

[12] N. K. F. Tsang, M. T. H. Lai, and R. Law, "Measuring e-service quality for online travel agencies," Journal of Travel and Tourism Marketing, vol. 27, no. 3, pp. 306-323, 2010.

[13] K. C. Lee and N. Chung, "Understanding factors affecting trust in and satisfaction with mobile banking in Korea: A modified DeLone and McLean's model perspective," Interacting with Computers, vol. 21 no. 5, pp. 385-392, 2009.

[14] D. J. Kim and Y. Hwang, "A study of mobile internet user's service quality perceptions from a user's utilitarian and hedonic value tendency perspectives," Information Systems Frontiers, vol. 14, issue 2, pp. 409-421, 2012.

[15] L. Chen, "A model of consumer acceptance of mobile payment," International Journal of Mobile Communications, vol. 6, no. 1, pp. 32-52, 2008.

[16] Y. S. Wang and Y. W. Liao, "The conceptualization and measurement of m-commerce user satisfaction," Computers in Human Behavior, vol. 23, no. 1, pp. 381-398, 2007.

[17] W. H. Delone and E. R. Mclean, "The DeLone and McLean model of information systems success: A ten-year update," Journal of Management Information Systems, vol. 19, no. 4, pp. 9-30, 2003.

[18] R. S. Algharabat and A. M. A. Zamil, "An empirical investigation of 3D-based information systems success for online retailers," International Journal of Technology Marketing, vol. 8, no. 3, pp. 316336, 2013.

[19] B. Evjemo, S. Akselsen, and A. Schürmann, "User acceptance of digital tourist guides lessons learnt from two field studies," HumanComputer Interaction. Interaction Design and Usability, SpringerVerlag Berlin Heidelberg: New York, 2007.

[20] D. H. Goh et al., "Determining services for the mobile tourist," Journal of Computer Information Systems, vol. 51, no. 1, pp. 31-40, 2010.

[21] M. Salo, "Sources of dissatisfaction: Mobile interaction with the real world and other mobile internet applications," in Proc. 46th Hawaii International Conference on System Sciences, Hawaii, USA, 2013, pp. 1113-1122.

[22] T. Zhou, "An empirical examination of initial trust in mobile banking," Internet Research, vol. 21, no. 5, pp. 527-540, 2011.
[23] M. Chae et al., "Information quality for mobile Internet services: A theoretical model with empirical validation," Electronic Markets, vol 12 , no. 1 , pp. 38-46, 2002.

[24] M. Kenteris, D. Gavalas, and D. Economou, "Mytilene e-guide: A multiplatform mobile application tourist guide exemplar," Multimedia Tools and Applications, vol. 54, no. 2, pp. 241-262, 2011.

[25] C. H. Chen and C. Y. Tsai, "Designing user interfaces for mobile entertaining devices with cross-cultural considerations," Usability and Internationalization, Spinger-Verlag Berlin Heidelberg: New York, 2007.

[26] F. Xiuqin, X. Xinping, and G. Huan, "The customer satisfaction evaluation of mobile industry based on multilevel structural equation model," Proceedings of Grey Systems and Intelligent Services Nanjing, China, pp. 947-951, 2009.

[27] J. F. Hair et al., Multivariate Data Analysis, 7th ed, New Jersey: Pearson Prentice Hall. 816. 2010

[28] J. C. Gu, S. C. Lee, and Y. H. Suh, "Determinants of behavioral intention to mobile banking," Expert Systems with Applications, vol 36, no. 9, pp. 11605-11616, 2009.

[29] C. Kim, M. Mirusmonov, and I. Lee, "An empirical examination of factors influencing the intention to use mobile payment," Computers in Human Behavior, vol. 26, no. 3, pp. 310-322, 2010.

[30] C. Y. Tsai, "An analysis of usage intentions for mobile travel guide systems," African Journal of Business Management, vol. 4, no. 13, pp. 2962-3970, 2010.

[31] S. Oh, X. Y. Lehto, and J. Park, "Travelers' intent to use mobile technologies as a function of effort and performance expectancy," Journal of Hospitality Marketing \& Management, vol. 18, no. 8, pp 765-781, 2009.

[32] J. K. Ayeh, N. Au, and R. Law, "Predicting the intention to use consumer-generated media for travel planning," Tourism Management, vol. 35, pp. 132-143, 2013.

[33] S. H. Kim, "Moderating effects of job relevance and experience on mobile wireless technology acceptance: Adoption of a smartphone by individuals," Information and Management, 2008, vol. 45, no. 6, pp. 387-393, 2008.

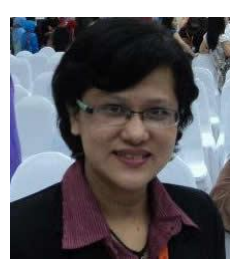

Numtip Trakulmaykee was born in Nakornsrithummarat, Thailand, in 1972. She received the $\mathrm{Ph} . \mathrm{D}$. degree in computer science from Universiti Sains Malaysia in 2014. She received two master degrees: one in management of information technology from Walailuk University, Thailand in 2006, and the other master degree is in business administration from Ramkhumheang University, Thailand in 2001. She received the B.S. degree in science and technology from Prince of Songkla University, Thailand in 1994.

She is currently a lecturer at Information and Communication Technology program (ICT) of Faculty of Science in Prince of Songkla University, Thailand. Her research interests are information technology, mobile application, technology adoption, mobile application in tourism, mobile learning, and knowledge management.

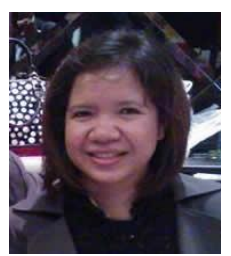

Yaowalak Trakulmaykee was born in Songkhla, Thailand, in 1970. She is studying a Ph.D. degree in human resource management from Universiti Sains Malaysia. She received a master degree in business administration from Ramkhumheang University, Thailand in 2001. She received the B.S. degree in public administration from Prince of Songkla University, Thailand in 1992

She is currently a lecturer at Hatyai Business School in Hatyai University, Thailand. Her research interests are tourism management, human resource management, job satisfaction, and employee turnover intention.

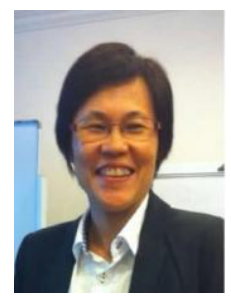

Khanungnit Hnuchek was born in Pattalung, Thailand, in 1972. She received a Ph.D. degree in business administration from Universiti Sain Malaysia in 2013. She received a master degree in business administration from Ramkhumheang University, Thailand in 2002. She received the B.S degree in finance and banking from Ramkhumheang University in 1995.

She is currently a lecturer at Hatyai Business School in Hatyai University, Thailand. Her research interests are marketing, franchise, and retailing management. 